Article

\title{
Identification of Pneumococcal Serotypes by PCR-Restriction Fragment Length Polymorphism
}

\author{
María del Mar García-Suárez ${ }^{1, *(0)}$, Irene González-Rodríguez ${ }^{2}$, María Dolores Cima-Cabal ${ }^{1}(\mathbb{D}$, \\ Jose Enrique Yuste ${ }^{3,4}$, Fernando Vazquez ${ }^{5,6,7,8}$ and Enrique Santiago 9 \\ 1 Escuela Superior de Ingeniería y Tecnología (ESIT), Universidad Internacional de La Rioja (UNIR), \\ 26006 Logroño, Spain; dolores.cima@unir.net \\ 2 Instituto de Productos Lácteos de Asturias (IPLA), 33300 Villaviciosa, Spain; \\ irenegonzalezrodriguez@hotmail.com \\ 3 Centro Nacional de Microbiología, Instituto de Salud Carlos III, 28220 Madrid, Spain; jyuste@isciii.es \\ 4 CIBER de Enfermedades Respiratorias, CIBERES, 28029 Madrid, Spain \\ 5 Servicio de Microbiología, Hospital Universitario Central de Asturias, 33011 Oviedo, Spain; \\ fvazquez@uniovi.es \\ 6 Área de Microbiología, Departamento de Biología Funcional, Universidad de Oviedo, 33006 Oviedo, Spain \\ 7 Fundación de Investigación Oftalmológica, Instituto Oftalmológico Fernández-Vega, 33012 Oviedo, Spain \\ 8 Instituto de Investigación Sanitaria del Principado de Asturias (ISPA), 33011 Oviedo, Spain \\ 9 Departamento de Biología Funcional, Universidad de Oviedo, 33006 Oviedo, Spain; esr@uniovi.es \\ * Correspondence: mar.garcia.suarez@unir.net
}

Received: 18 October 2019; Accepted: 15 November 2019; Published: 18 November 2019

\begin{abstract}
Streptococcus pneumoniae shows more than 90 capsular serotypes that can be distinguished by their reactivity against antisera. The main objective of this work was the development of a molecular method for serotyping without the use of antisera. A computer program containing an algorithm was used to search in a database for potentially useful enzymes for Restriction Fragment Length Polymorphism-RFLP typing, in order to maximize the discrimination between different serotypes. DNA sequences of 90 serotypes for the region between dex $\mathrm{B}$ and aliA genes were compiled, and a computer screening of restriction enzymes was performed. The $w z g-w z h-w z d-w z e$ region and Sse9I restriction predicted unique PCR-RFLP patterns for 39 serotypes and eight serogroups. A second restriction enzyme resolved fragment specific patterns for 25 serotypes. The method was tested with 98 serotype-unknown clinical isolates. PCR-RFLP analysis deduced correct serotypes that were confirmed by Quellung reaction for 78.5\% of the isolates.
\end{abstract}

Keywords: Streptococcus pneumoniae; serotype; PCR-RFLP

\section{Introduction}

Streptococcus pneumoniae produces infections such as meningitis, pneumonia, otitis or septicemia, which cause high mortality and morbidity rates in children and adults around the world. In children under 5 years of age, it is estimated that pneumococcus produces at least 3.7 million episodes of severe infections, accounting for up to 0.5 million deaths per year [1,2]. S. pneumoniae colonizes asymptomatically the nasopharynx of the majority of the population, especially in healthy children. From this reservoir, the infections and transmission between individuals occurs.

Evaluation of prevalent pneumococcal colonizing serotypes in the population is important because they are the main source of infections. In addition, since the introduction of the first conjugate vaccine (PCV-7) in 2000, two significant events were observed. First, a reduction in the number of invasive pneumococcal disease (IPD) by vaccine serotypes. Second, a replacement of serotypes causing IPD with the appearance of serotypes not included in the vaccine $[3,4]$. Serotype "switching" occurred in 
some cases by genetic recombination in the capsular locus, allowing the pneumococcus to escape the immunity acquired by the vaccines, which can have important consequences in the future $[5,6]$.

The capsule is the principal line of defense against non-specific host immunity and the main virulence factor of S. pneumoniae. Chemical and antigenic variability of the capsule allows for the classifying of the pneumococcal population in 49 groups and more than 90 different serotypes $[7,8]$. The genes for the pneumococcal capsular polysaccharides (CPS) are located at the same chromosomal locus (cps) - between dexB and aliA [9]. The capsular polysaccharides of the most prevalent serotypes were used in the generation of the first polysaccharide vaccine (PPV-23), containing 23 different CPS, and later in the commercialization of conjugate vaccines 7,10 , or 13-valent conjugate vaccines (PCV-7, $-10,-13)[1,10]$. PCV-7 targeted serotypes 4, 6B, 9V, 14, 18C, 19F, and 23F. PCV-10 included also serotypes $1,5,7 \mathrm{~F}$, and, in PCV-13, serotypes 3, 6A and 19A were also added.

Detecting all the serotypes present in the nasopharynx is the key to making a good epidemiological surveillance to evaluate the impact of vaccines in the carrier state of the population. So far, the researchers serotyped isolated colonies of $S$. pneumoniae previously grown on blood agar plates, with limited identification for culture-negative samples. Molecular techniques have allowed to detect an increase in individuals colonized by more than one serotype. Additionally, other authors have revealed a multitude of genetic variations and the presence of capsular genes in other species [11]. Given the diversity of techniques used so far, WHO has given a series of recommendations to improve pneumococcal serotypes detection [12].

The gold standard for pneumococcal serotyping is the Quellung reaction [13]. This method is laborious because it requires several steps with expensive antisera. Latex agglutination is an alternative, and a cheaper option than Quellung reaction, but also requires culture of the isolates. Alternative typing methods not based in antisera are described for S. pneumoniae using DNA molecular methods: multiplex PCR [14-16], real-time PCR, microchip, sequencing-typing, reverse-hybridization, MALDI-TOF MS, and whole genome sequencing [8,17-19].

In this study, we report a PCR-RFLP method capable of amplifying a relatively small fragment located in the capsule locus. A statistical algorithm was used to select the best set of enzymes to discriminate the different serotypes. We have found that the digestion of the amplicons with one or two restriction enzymes yields unique patterns for 63 serotypes of $S$. pneumoniae.

\section{Materials and Methods}

\subsection{In Silico Evaluation of Restriction Enzymes}

We used an adaptation of an informatic tool [20] which analyses the efficiency of all the combinations of pairs of restriction enzymes among a set of 193 type-II restriction enzymes (Table S1) from the Rebase database [21], to specifically detect the differences between 90 DNA sequences of S. pneumoniae serotypes for the region defined by $w z g-w z h-w z d-w z e$ genes from the GenBank databases. Data generated were useful to calculate the sizes of the digestion fragments of each S. pneumoniae serotype and for each restriction enzyme or pair of enzymes. Briefly, the program defines the S. pneumoniae serotypes depending on the pattern of fragment sizes. The different S. pneumoniae serotypes share the same pattern if all the fragment sizes of one type are present in the other type and vice versa. The program takes into account the resolution of the electrophoresis and marks a minimum size of fragments that can be easily observed in the gels. In addition, the program analyzed the fragments produced by the restriction enzymes, investigating the enzymes in pairs.

The statistical score of a restriction enzyme for the discrimination between serotypes is calculated from a $m \times 90$ table, where $m$ is the number of different patterns generated by the enzyme and 90 is the number of serotypes. Ideally, the maximum number of different patterns should be 90 . Ones are included in cells corresponding to each serotype (j) and its particular pattern (i). The other cells are filled with zeroes. At the end, cells including the number one in the table connect the serotypes to their patterns. The number $n_{i j}$ in cell at row $i$ and column $j$ is the number of types which share the particular 
pattern $\mathrm{i}$, and the same serotype, $\mathrm{j}$. A Chi-square $\left(\chi^{2}\right)$ value is calculated from this contingency table using the equation:

$$
\chi^{2}=\sum_{\mathrm{i}=1}^{m} \sum_{\mathrm{j}=1}^{90} \frac{\left(\mathrm{n}_{\mathrm{ij}}-\mathrm{e}_{\mathrm{ij}}\right)^{2}}{\mathrm{e}_{\mathrm{ij}}}
$$

where $\mathrm{e}_{\mathrm{ij}}=\frac{r_{i} c_{i}}{90}, r_{i}=\sum_{\mathrm{j}=1}^{90} \mathrm{n}_{\mathrm{ij}}$ and $c_{j}=\sum_{\mathrm{i}=1}^{m} \mathrm{n}_{\mathrm{ij}}$ where $\mathrm{n}_{\mathrm{ij}}$ is either 1 or 0 .

\subsection{Pneumococcal Isolates}

Pneumococcal collection type strains were obtained from CCUG (Culture Collection University of Göteborg, Göteborg, Sweden) and Sanger Institute (Cambridgeshire, UK). Clinical isolates (98) were obtained from the Microbiology Department, Hospital Universitario Central de Asturias (Oviedo, Spain), the Spanish Pneumococcal Reference Laboratory (SPRL), National Center for Microbiology (Madrid, Spain) and University of Adelaide (Adelaide, Australia).

\subsection{PCR Amplification of S. pneumoniae cps Genes}

For PCR amplification, bacterial cells were harvested from a fresh overnight culture on blood agar plates, and a dense suspension of cells was dissolved in $100 \mu \mathrm{L}$ of $\mathrm{ddH}_{2} \mathrm{O}$. Multiplex PCR amplifications were carried out with the primers GHDE-F-7m $(0.5 \mu \mathrm{M})$, GE-R-32m $(0.8 \mu \mathrm{M})$, SER3-F-1 $(0.1 \mu \mathrm{M})$, SER3-R-108 $(0.1 \mu \mathrm{M})$, GE-R-34, GLF-F-151, and GE-R-38 (Table S4). The reactions mix was carried out in a volume of $50 \mu \mathrm{L}$, with 0.5 units of HotMaster Taq Polymerase (5PRIME, VWR International Eurolab, Barcelona, Spain), buffer $1 \times, \mathrm{MgCl}_{2} 1.5 \mathrm{mM}$, dNTPs $10 \mathrm{mM}$ each, and $5 \mu \mathrm{L}$ of cell suspensions. PCR was undertaken in a T-personal Thermocycler (Biometra, Göttingen, Germany) with initial denaturation at $94{ }^{\circ} \mathrm{C}$ for $5 \mathrm{~s}$, followed by 30 cycles of $94{ }^{\circ} \mathrm{C}$ for $5 \mathrm{~s}, 48^{\circ} \mathrm{C}$ for $20 \mathrm{~s}$ and $65^{\circ} \mathrm{C}$ for $10 \mathrm{~min}$, and a final extension at $65^{\circ} \mathrm{C}$ for $10 \mathrm{~min}$.

\subsection{Analysis of Fragments Obtained from Enzyme Digestions}

Ten microliters of PCR products were digested with different restriction enzymes (Sse9I, AluI, MseI, BfuCI, BstDEI, EsaBC3I, HpyCH4IV) in an appropriate restriction buffer to a total volume of $50 \mu \mathrm{L}$. After incubation for $3 \mathrm{~h}$ at the recommended temperature, the digested DNA was electrophoresed on a $2.5 \%$ non-denaturing polyacrylamide gel with $1.5 \%$ of Spreadex polymer (Elchrom Scientific, Cham, Switzerland), and the sizes of the fragments were estimated by comparison with 20-bp ladder (Lonza Rockland, Inc, Rockland, ME, USA).

\subsection{Serotyping of Clinical Isolates}

Conventional serotyping was performed by the Quellung reaction and a dot blot assay, using rabbit polyclonal antisera from the Statens Serum Institute, Copenhagen, Denmark, as previously described [22], at SPRL, Madrid, Spain.

\section{Results}

\subsection{In Silico Analysis of GenBank Sequences}

The genes $w z g-w z h-w z d-w z e$, located in the locus $c p s$, were tested by a computer screening of restriction enzymes. Virtually, the resolution of the electrophoresis system could be maximum, $0 \%$ (when the fragments with different lengths are always identified as different fragments), or minimum, $10 \%$ (when two fragments differing by less than $10 \%$ are considered to be the same fragment). Serotype discrimination reaches higher levels when the fragments generated by the enzymes differ the most from each other. Ideally, for 90 serotypes the number of different fragment patterns should be 90 , but we cannot obtain this number by testing either single or double enzyme digestions. Two restriction 
enzymes, Sse9I and CviJ, showed better scores of discrimination among serotypes (Figure 1) than the rest of enzymes, since they generated 60 and 55 different patterns, respectively, at an electrophoresis resolution of $1 \%$.

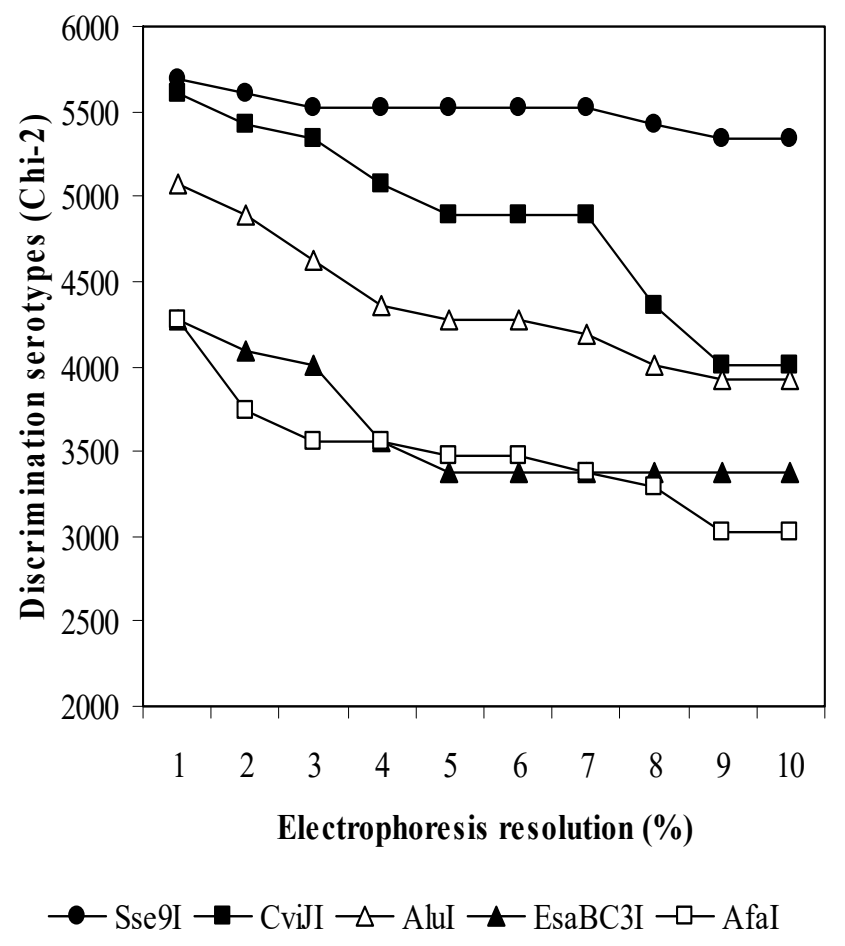

Figure 1. Discrimination values between serotypes by analysis of fragments produced by digestions with different restriction enzymes in the region $w z g-w z h-w z d-w z e$. The values are given as a function of the resolution of the electrophoresis system. All the fragments of $100 \mathrm{bp}$ and over are considered for the analysis.

\subsection{Generation of a Preliminary Database of Fragment Patterns.}

Sequences from GenBank corresponding to the region wzg-wzh-wzd-wze were tested by informatic analysis with Sse9I ( . . \AATT ... ) (NIPPON Genetics Europe, Germany) and the fragment patterns obtained generated the initial database with different pattern fragments (Table S2a). In this database, sequences belonging to 39 serotypes $(1,3,4,5,6 \mathrm{~A}, 6 \mathrm{~B}, 7 \mathrm{C}, 8,10 \mathrm{~A}, 10 \mathrm{~B}, 11 \mathrm{~F}, 12 \mathrm{~B}, 14,15 \mathrm{~A}, 15 \mathrm{~F}, 18 \mathrm{~A}$, 18C, 19A, 19B, 19C, 19F, 21, 23A, 23B, 23F, 24A, 24F, 27, 31, 33B, 33C, 33D, 34, 37, 41F, 43, 45, 47A, and 48) showed unique fragment patterns. In six cases we also have detected two fragment patterns for the same serotype $\left(6 \mathrm{~A}, 6 \mathrm{~B}, 8,18 \mathrm{C}, 23 \mathrm{~F}\right.$ and $24 \mathrm{~A}$, see patterns $\mathrm{n}^{\circ} 7$ and 8, 9 and 10, 42 and 43). Sixteen serotypes showed the same pattern as another serotype within same serogroup (see patterns $\mathrm{n}^{\circ} 11,15$, $16,19,21,28,39$ and 49). Sequences belonging to 37 serotypes showed the same pattern as another serotypes (see patterns $\mathrm{n}^{\circ} 2,12,20,23,25,30,31,47,50,56$ ).

For discrimination of serotypes without a unique fragment pattern, the informatic tool was used to predict the optimal secondary restriction enzymes. The results obtained showed that the following enzymes could be used to discriminate: 7A and 7F: BfuCI; 9L and 9N: BstDEI, CviAII, HinfI; 11B and 11C: MseI; 13 and 20: MseI, Bst4CI; 25A and 25F: HpyCH4IV; 28A and 28F: MseI, AluI, Bst4CI, EsaBC3I; 29 and 39: MseI, HpyCH4IV, EsaBC3I; 33D and 41F: MseI, HpyCH4IV, EsaBC3I; 35F and 47F: EsaBC3I. A second restriction enzyme resolved a fragment-specific pattern for sequences belonging to 25 serotypes: 7A, 7F, 9L, 9N, 11B, 11C, 12F, 13, 16A, 17A, 17F, 20, 25A, 25F, 28A, 28F, 29, 33D, 35F, 36, 39, 41F, 42, 44, and $47 \mathrm{~F}$ (Table S3). However, due to similarity of sequences, serotypes $2 / 41 \mathrm{~A}, 7 \mathrm{~B} / 40,9 \mathrm{~A} / 9 \mathrm{~V}, 10 \mathrm{C} / 10 \mathrm{~F}$, $11 \mathrm{~A} / 11 \mathrm{D} / 18 \mathrm{~F}, 12 \mathrm{~A} / 46,15 \mathrm{~B} / 15 \mathrm{C}, 18 \mathrm{~B} / 18 \mathrm{C}, 22 \mathrm{~A} / 22 \mathrm{~F}, 32 \mathrm{~A} / 32 \mathrm{~F}$ and $33 \mathrm{~A} / 33 \mathrm{C} / 33 \mathrm{~F} / 35 \mathrm{~A} / 35 \mathrm{~B} / 35 \mathrm{C}$ could not be discriminated using the PCR-RFLP method. 


\subsection{PCR-RFLP Analysis of S. pneumoniae Collection Type Strains}

To validate the database of fragment patterns, 37 collection type strains of S. pneumoniae (Table 1) were tested by PCR-RFLP analysis. First, we tried to amplify all serotypes with the primers GHDE-F-7m and GE-R-32m, but repeatedly, no amplification products were found for some strains. In order to amplify all serotypes of $S$. pneumoniae, PCR primers were designed to include specifically the serotypes 3, 25, 29, 38, 39 and 43 (Table S4, Figure S1). PCR was performed in suspensions of colonies and PCR products were obtained from all strains (Figure S2). As expected, PCR-RFLP from collection type strains belonged to the following serotypes 1, 2, 3, 4, 5, 6B, 9A, 10B, 10F, 11A, 11B, 11D, 12A, 12B, 14, 18C, 19A, 19F, 20, 21, 24F, 27, 31, 32A, 33D, 33F, 35A, 40, 42, 45 and 48, which showed patterns already included in the initial fragment database. Surprisingly, the reference strains with serotypes 7A, 10C, 19C, 22F, 34 and 36, showed fragment patterns distinct to those calculated based on the sequence from the database. These patterns were identified (Table S2b) and added to the initial database.

Table 1. Pneumococcal collection type strains used in the study.

\begin{tabular}{|c|}
\hline Strain \\
\hline S. pneumoniae serotype 1 CCUG $2839 \mathrm{~A}^{\mathrm{a}}$ \\
\hline S. pneumoniae serotype 2 CCUG $8435^{\text {a }}$ \\
\hline S. pneumoniae serotype $3 \mathrm{~GB} 05^{\mathrm{b}}$ \\
\hline S. pneumoniae serotype 4 CCUG $2226^{\text {a }}$ \\
\hline S. pneumoniae serotype 5 CCUG $2541^{\text {a }}$ \\
\hline S. pneumoniae serotype 6B CCUG $1350^{\mathrm{a}}$ \\
\hline S. pneumoniae serotype 7A CCUG $8436^{\text {a }}$ \\
\hline S. pneumoniae serotype 9A CCUG $3506^{\text {a }}$ \\
\hline S. pneumoniae serotype 10B Sri Lanka ${ }^{b}$ \\
\hline S. pneumoniae serotype $10 \mathrm{C} / 1$ Sanger ${ }^{\text {b }}$ \\
\hline S. pneumoniae serotype $10 \mathrm{~F}$ CCUG $5697^{\mathrm{a}}$ \\
\hline S. pneumoniae serotype 11A CCUG $36617^{\text {a }}$ \\
\hline S. pneumoniae serotype 11B CCUG $8440^{\text {a }}$ \\
\hline S. pneumoniae serotype $11 \mathrm{D}$ Sanger $70 / 86^{\mathrm{b}}$ \\
\hline S. pneumoniae serotype $12 \mathrm{~A}$ CCUG $8444^{\text {a }}$ \\
\hline S. pneumoniae serotype $12 \mathrm{~B}$ Gambia $1 / 81^{\text {b }}$ \\
\hline S. pneumoniae serotype 14 CCUG $1086 \mathrm{~B}^{\mathrm{a}}$ \\
\hline S. pneumoniae serotype $18 \mathrm{C}$ Sanger $4593 / 4$ b \\
\hline S. pneumoniae serotype 19A Sanger $1773 / 39^{\mathrm{b}}$ \\
\hline S. pneumoniae serotype 19 C Sanger $408 / 41^{\text {b }}$ \\
\hline S. pneumoniae serotype 19F CCUG $1407^{\text {a }}$ \\
\hline S. pneumoniae serotype 20 CCUG $8451^{\text {a }}$ \\
\hline S. pneumoniae serotype 21 CCUG $1697^{\text {a }}$ \\
\hline S. pneumoniae serotype $22 \mathrm{~F}$ Sanger $1772 / 40^{\mathrm{b}}$ \\
\hline S. pneumoniae serotype $24 \mathrm{~F} \mathrm{CCUG} 8457^{\text {a }}$ \\
\hline S. pneumoniae serotype 27 CCUG $5898^{\text {a }}$ \\
\hline S. pneumoniae serotype 31 CCUG $6956^{\text {a }}$ \\
\hline S. pneumoniae serotype $32 \mathrm{~A}$ CCUG $8458^{\text {a }}$ \\
\hline S. pneumoniae serotype 33D India b \\
\hline S. pneumoniae serotype 33F Sanger $3077 / 37$ b \\
\hline S. pneumoniae serotype 34 CCUG $2399^{\text {a }}$ \\
\hline S. pneumoniae serotype 35 A CCUG $3556^{\text {a }}$ \\
\hline S. pneumoniae serotype 36 CCUG $5906^{\text {a }}$ \\
\hline S. pneumoniae serotype 40 CCUG $8468^{\text {a }}$ \\
\hline S. pneumoniae serotype 42 CCUG $6568^{\text {a }}$ \\
\hline S. pneumoniae serotype 45 CCUG $8472^{\text {a }}$ \\
\hline S. pneumoniae serotype 48 CCUG $8476^{\mathrm{a}}$ \\
\hline
\end{tabular}

${ }^{a}$ CCUG, Culture Collection University of Göteborg, and ${ }^{\mathrm{b}}$ Sanger Institute (Cambridgeshire, UK). 


\subsection{Serotype Identification of Clinical Isolates by PCR-RFLP Analysis}

In order to check the potential of the PCR-RFLP method, 98 clinical isolates with an unknown serotype were tested in a blinded fashion. Amplification was obtained for all isolates, except one (95.5\%). PCR-RFLP with Sse9I from some clinical isolates are shown in Figure 2. The fragment patterns were easily obtained and compared with the database to obtain the corresponding serotype. A total of 77 isolates $(78.5 \%)$ were serotyped correctly (i.e., in agreement with Quellung reaction results) including 26 serotypes (73.2\%): $1(n=3), 2(n=1), 3(n=8), 4(n=4), 7 \mathrm{~F}(n=7), 8(n=4), 9 \mathrm{~N}(n=2)$, $9 \mathrm{~V}(n=3), 10 \mathrm{~A}(n=1), 11 \mathrm{~A}(n=4), 12 \mathrm{~F}(n=2), 14(n=6), 15 \mathrm{~A}(n=1), 16 \mathrm{~F}(n=2), 19 \mathrm{~A}(n=3)$, 19F $(n=1), 22 \mathrm{~F}(n=3), 23 \mathrm{~B}(n=2), 23 \mathrm{~F}(n=7), 24 \mathrm{~F}(n=1), 28 \mathrm{~A}(n=1), 29(n=1), 33 \mathrm{~F}(n=2), 34$ $(n=2), 35 \mathrm{~B}(n=2), 35 \mathrm{~F}(n=2)$ (Table 2). Additionally, 21 isolates revealed 15 new PCR-RFLP fragment patterns, corresponding to serotypes $6 \mathrm{~A}, 6 \mathrm{~B}, 7 \mathrm{~F}, 12 \mathrm{~F}, 13,14,15 \mathrm{~A}, 15 \mathrm{~B}, 17 \mathrm{~F}, 18 \mathrm{C}, 19 \mathrm{~A}$ and $24 \mathrm{~F}$ (Table S2c). As expected, for the two non-typeable isolates no amplification was achieved. Clinical isolates had been obtained from different geographical regions in Spain (except serotype 7F and 8, from University of Adelaide) containing the 32 serotypes: 1, 2, 3, 4, 6A, 6B, 7F, 8, 9N, 9V, 10A, 11A, 12F, 13, 14, 15A, 15B, 16F, 17F, 18C, 19A, 19F, 22F, 23B, 23F, 24F, 28A, 29, 33F, 34, 35B, 35F. Serotyping of the strains was done at the Spanish Pneumococcal Reference Laboratory, using Quellung reaction.

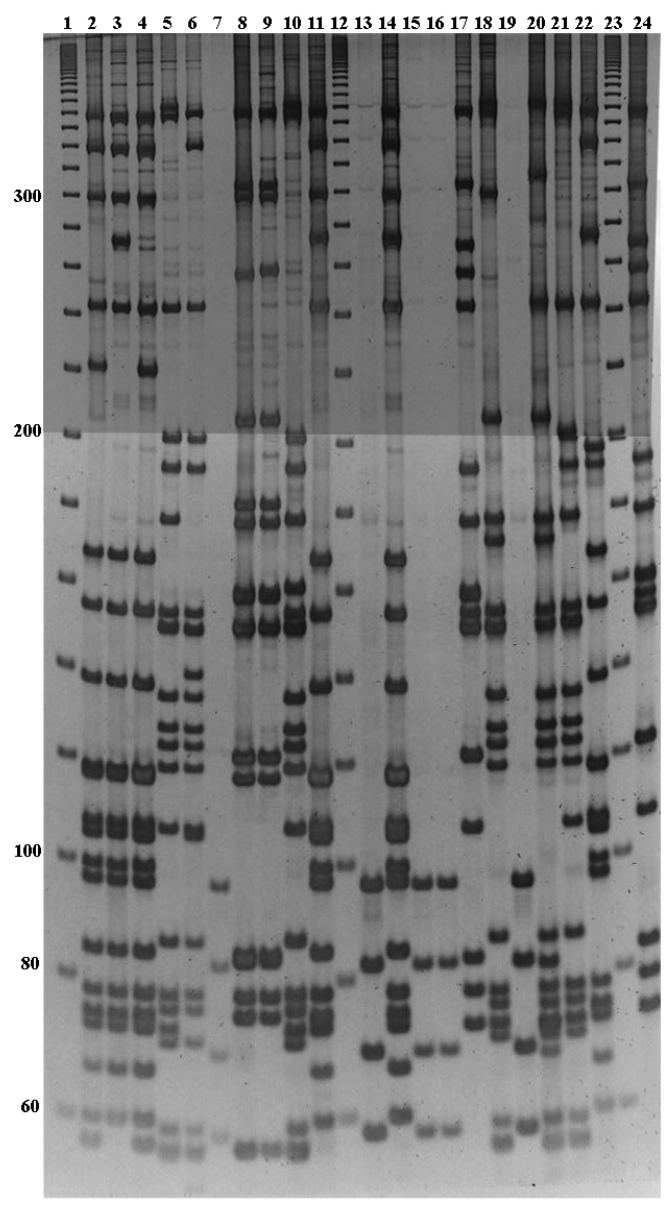

Figure 2. Identification of serotypes from Sse9I fragments in polyacrylamide gels stained with SYBR Green I. Lane 1, 20 bp ladder; lane 2, serotype 14; lane 3, serotype 7A/7F; lane 4, serotype 14; lane 5, serotype 22F; lane 6, serotype 8; lane 7, serotype 3; lane 8, serotype 6B; lane 9, serotype 6B; lane10, serotype 17A/17F/33A/33F/35/42; lane11, serotype 7A/7F; lane12, 20 bp ladder; lane 13, serotype 3; lane14, serotype 7A/7F; lane 15, serotype 3; lane 16, serotype 3; lane 17, serotype 11A/11D/18F; lane 18, serotype 28A/28F; lane 19, serotype 3; lane 20, serotype 12F; lane 21, serotype 22F; lane 22, serotype 16F; lane 23, 20 bp ladder; lane 24, serotype 11A/11D/18F. 
Table 2. Summary of PCR-RFLP analysis of clinical isolates.

\begin{tabular}{|c|c|c|c|c|}
\hline Serotype & $\mathbf{N}^{\circ}$ Isolates & Origin & $\begin{array}{c}\mathrm{N}^{\circ} \text { Concordant } \\
\text { Patterns ( } \mathrm{n}^{\circ} \text { Strains) }\end{array}$ & $\begin{array}{c}\mathrm{N}^{\circ} \text { New Patterns } \\
\text { (n }{ }^{\circ} \text { Strains) }\end{array}$ \\
\hline 1 & 3 & ${ }^{\text {a }}$ SPRL & $3(3)$ & \\
\hline 2 & 1 & ${ }^{\mathrm{b}} \mathrm{HUCA}$ & $1(1)$ & \\
\hline 3 & 8 & SPRL & $8(8)$ & \\
\hline 4 & 4 & HUCA, SPRL & $4(4)$ & \\
\hline $6 \mathrm{~A}$ & 1 & HUCA & & $1(1)$ \\
\hline $6 \mathrm{~B}$ & 3 & HUCA & & $2(3)$ \\
\hline $7 \mathrm{~F}$ & 8 & ${ }^{\mathrm{C}} \mathrm{UA}, \mathrm{SPRL}$ & $7(7)$ & 1(1) \\
\hline 8 & 4 & UA, SPRL & $4(4)$ & \\
\hline $9 \mathrm{~N}$ & 2 & HUCA, SPRL & $2(2)$ & \\
\hline $9 \mathrm{~V}$ & 3 & HUCA, SPRL & $3(3)$ & \\
\hline $10 \mathrm{~A}$ & 1 & SPRL & $1(1)$ & \\
\hline $11 \mathrm{~A}$ & 4 & HUCA, SPRL & $4(4)$ & \\
\hline $12 \mathrm{~F}$ & 3 & ${ }^{\mathrm{d}} \mathrm{CNM}, \mathrm{SPRL}$ & $2(2)$ & $1(1)$ \\
\hline 13 & 1 & HUCA & & $1(1)$ \\
\hline 14 & 7 & HUCA, SPRL & $6(6)$ & $1(1)$ \\
\hline $15 \mathrm{~A}$ & 2 & SPRL & $1(1)$ & $1(1)$ \\
\hline $15 B$ & 1 & CNM & & $1(1)$ \\
\hline $16 \mathrm{~F}$ & 2 & SPRL & $2(2)$ & \\
\hline $17 \mathrm{~F}$ & 1 & CNM & & $1(1)$ \\
\hline $18 \mathrm{C}$ & 1 & SPRL & & $1(1)$ \\
\hline $19 \mathrm{~A}$ & 11 & SPRL & $3(3)$ & $3(8)$ \\
\hline $19 \mathrm{~F}$ & 1 & HUCA & $1(1)$ & \\
\hline $22 \mathrm{~F}$ & 3 & HUCA, SPRL & $3(3)$ & \\
\hline $23 \mathrm{~B}$ & 2 & SPRL & $2(2)$ & \\
\hline $23 \mathrm{~F}$ & 7 & HUCA, SPRL & $7(7)$ & \\
\hline $24 \mathrm{~F}$ & 2 & SPRL & $1(1)$ & $1(1)$ \\
\hline $28 \mathrm{~A}$ & 1 & SPRL & $1(1)$ & \\
\hline 29 & 1 & SPRL & $1(1)$ & \\
\hline $33 \mathrm{~F}$ & 2 & SPRL & $2(2)$ & \\
\hline 34 & 2 & HUCA, SPRL & $2(2)$ & \\
\hline $35 B$ & 2 & SPRL & $2(2)$ & \\
\hline $35 \mathrm{~F}$ & 2 & HUCA, SPRL & $2(2)$ & \\
\hline NT & 2 & SPRL & $2(2)$ & \\
\hline Total & 98 & & 77 (77) & $15(21)$ \\
\hline
\end{tabular}

${ }^{a}$ Clinical isolates from Spanish Pneumococcal Reference Laboratory, SPRL ( ${ }^{\circ}$ strains): serotype 1 (3), serotype 3 (9), serotype 4 (3), serotype 7F (8), serotype 8 (3), serotype $9 \mathrm{~N}$ (1), serotype 10A (1), serotype 11 (3), serotype 12F (2), serotype 14(6), serotype 15A (2), serotype 16F (2), serotype 18C (1), serotype 19A (11), serotype 22F(2), serotype 23B (2), serotype $23 \mathrm{~F}(1)$, serotype $24 \mathrm{~F} \mathrm{(2),} \mathrm{serotype} 28$ (1), serotype 29 (1), serotype $33 \mathrm{~F}$ (2), serotype 34 (1), serotype $35 \mathrm{~B}$ (2), serotype $35 \mathrm{~F}$ (1), NT, non-typeable (2). ${ }^{\mathrm{b}}$ Clinical isolates from Hospital Universitario Central de Asturias, HUCA: S. pneumoniae serotype 2 (strain 99/18413), serotype 4 (strain 08/2751), serotype 6A (strain 99/23686), serotype 6B (strain 99/34320), serotype 6B (strain 08/2720), serotype 6B (strain 99/16243), serotype 9N (strain 00/14800), serotype $9 \mathrm{~V}$ (strain 99/39253), serotype 9V (strain 00/10762), serotype 11A (strain 99/22279), serotype 13 (strain 99/34157), serotype 14 (strain 00/37682), serotype 19F (strain 00/8339), serotype 22F (strain 99/29369), serotype 23F (strain 00/42913), serotype 23F (strain 1655 Badalona), serotype 23F (strain 99/17077), serotype 23F (strain 99/30466), serotype 23F (strain 08/2721), serotype 34 (strain 00/3495), serotype $35 \mathrm{~F}$ (strain 00/1522). ${ }^{\mathrm{c}}$ Clinical isolates from University of Adelaide: S. pneumoniae serotype 7F UA, S. pneumoniae serotype $8 \mathrm{UA} .{ }^{\mathrm{d}}$ Clinical isolates from Centro Nacional de Microbiología, CNM: S. pneumoniae serotype 9V CNM, serotype 10A CNM, serotype 12F CNM, serotype 15B CNM, serotype $17 \mathrm{~F}$ CNM.

\section{Discussion}

In this report, we describe a molecular method to identify the 63 serotypes and eight serogroups of S. pneumoniae without the use of antiserum. We have attempted to develop an approach to serotyping using the same PCR primers for all the serotypes and an RFLP step for resolution of the serotype/serogroup. In the PCR-RFLP approach, the selection of sequences within the cps gene cluster is critical, as well as the particular set of restriction enzymes used to generate fragments. A computer program previously developed to discriminate HPV types [20] was modified to search for the optimal 
restriction enzyme for discriminating the 90 S. pneumoniae serotypes. The selection of the sequences $w z g-w z h-w z d-w z e$ allowed to obtain PCR amplifications with an acceptable size to facilitate positive amplifications in all the strains. It also allowed easy interpretation of agarose gels and database. Previous reports used for PCR-RFLP large fragments as the region between cpsA-cpsB and the region between dexB-aliA [23-25]. On the other hand, several methods, using different sizes of amplicons to differentiate serotypes, have been described [14,15,26,27].

Although Quellung reaction has been considered the gold standard technique for pneumococcal serotyping [28-30], this technique is time-consuming, and the need for a diverse panel of specific antisera makes the test very expensive in order to identify the group, type and factor. These problems might be solved by using molecular methods such as real-time PCR, multiplex-PCR, capsular sequence typing, or whole genome sequencing [31-35].

There are many other advantages in using the presented method to type pneumococci. The choice of Taq polymerase and the purification of high-quality DNA were not critical aspects for good quality patterns, since amplification products were obtained using the PCR primers described in this report, which are smaller than dexB-aliA amplifications previously reported. Furthermore, direct amplification from cell suspensions simplifies the routine assays and reduces time-consuming DNA purification protocols. Multiplex PCR with a reduced number of primers provides a cost-effective method. Furthermore, the serotypes tested in the current study, included those approved by the FDA regarding the heptavalent pneumococcal conjugate vaccine PCV7, PCV10, PCV13, and phase III clinical trials with a fifteen-valent PCV [36], and all of the 23 serotypes in the PPV23 vaccine.

After the introduction of pneumococcal conjugate vaccines, an increase in specific serotypes causing IPD in both children and adults occurred. In Spain, pneumococcal vaccines became available for private purchase in 2001 (PCV7), 2009 (PCV10) and 2010 (PCV13). Overall, non-PCV13 serotypes have raised in recent years, contributing to the current burden of IPD cases in children and adults [4,37]. Moreover, high colonization rates have been observed in Spanish children, with serotypes 19A, 16F and $15 \mathrm{~B}$ being the most prevalent [38]. Other serotypes, such as $19 \mathrm{~A}, 3$ and $6 \mathrm{~A}$, remain important contributors to IPD after PCV13. In Europe, the most prevalent serotypes causing community-acquired pneumonia in adults are included in PCV13, and bacteraemic pneumonia is mainly caused by serotypes $1,3,7 \mathrm{~F}, 19 \mathrm{~A}$ and 14 [39,40]. The PCR-RFLP system described here may be used to easily discriminate the prevalent serotypes 1, 3, 6A, 14 and 19A, included in PCV13, as well as non-PCV13 serotypes such as $24 \mathrm{~F}, 23 \mathrm{~B}$ and $10 \mathrm{~A}$.

Due to similarity of sequences, serotypes $2 / 41 \mathrm{~A}, 7 \mathrm{~B} / 40,9 \mathrm{~A} / 9 \mathrm{~V}, 10 \mathrm{C} / 10 \mathrm{~F}, 11 \mathrm{~A} / 11 \mathrm{D} / 18 \mathrm{~F}, 12 \mathrm{~A} / 46$, $15 \mathrm{~B} / 15 \mathrm{C}, 18 \mathrm{~B} / 18 \mathrm{C}, 22 \mathrm{~A} / 22 \mathrm{~F}, 32 \mathrm{~A} / 32 \mathrm{~F}$ and $33 \mathrm{~A} / 33 \mathrm{C} / 33 \mathrm{~F} / 35 \mathrm{~A} / 35 \mathrm{~B} / 35 \mathrm{C}$ could not be discriminated using the PCR-RFLP method described and should be monitored using specific serotype primers, previously described (http://www.cdc.gov/streplab/pcr.html), or sequencing. One of the limitations of this paper is that it does not include serotypes 6C, 6D, and some genetic variants described [41-43].

Furthermore, the appearance of new patterns reveals the constant change of capsular genes, especially among serotypes exposed to the pressure of immunization, and the diversity within pneumococcal cps locus sequences, as previously described [5]. The database should always remain open to include changes that will take place in the future with the implementation of new vaccines.

In summary, the PCR-RFLP analysis of the cps genes with Sse9I digestion proved to be an adequate tool for the correct serotyping of almost all prevalent serotypes and serogroups of S. pneumoniae. This method needs few PCR primers and one or two restriction enzymes, making it technically assumable by most research laboratories and pneumococcal reference laboratories.

Supplementary Materials: The following are available online at http://www.mdpi.com/2075-4418/9/4/196/s1, Table S1: Restriction enzymes considered for discrimination among 90 S. pneumoniae serotypes, Table S2a: Sse9I fragment sizes obtained by analysis of GenBank sequences of the 90 S. pneumoniae serotypes. Table S2b: New patterns obtained by PCR-RFLP analysis of reference strains. Table S2c: New patterns obtained by PCR-RFLP analysis of clinical isolates. Table S3: Patterns obtained with secondary restriction enzymes. Table S4: Oligonucleotide primers used for multiplex PCR in this study. Figure S1. Location of specific primers for serotypes $3,25,38,29,39$ and 43 in cps locus. Figure S2. PCR products obtained from clinical isolates. 
Author Contributions: Conceptualization, E.S. and F.V.; methodology, M.d.M.G.-S.; software, E.S.; validation, I.G.-R., M.D.C.-C. and M.d.M.G.-S.; investigation, J.E.Y. and I.G.-R.; resources, J.E.Y.; writing-original draft preparation, M.d.M.G.-S.; writing—review and editing, M.d.M.G.-S., J.E.Y. and E.S.; funding acquisition, F.V. and M.D.C.-C.

Funding: This research was funded by University of Oviedo (UNOV-08-MB-3) and Ministerio de Educación y Cultura (MEC-06-BIO2006-1533-C04-02) of Spain and the APC was funded by Universidad Internacional de La Rioja (UNIR).

Acknowledgments: We sincerely thank A. Fenoll (Centro Nacional de Microbiologia, Instituto de Salud Carlos III, Spain), J.C. Paton (University of Adelaide, Australia) and A. Fleites (Hospital Universitario Central de Asturias, Spain) for providing us S. pneumoniae strains and Biozell Diagnostico Molecular for technical assistance.

Conflicts of Interest: The authors declare no conflict of interest. The funders had no role in the design of the study; in the collection, analyses, or interpretation of data; in the writing of the manuscript, or in the decision to publish the results.

\section{References}

1. World Health Organization. Estimated Hib and Pneumococcal Deaths for Children under 5 Years of Age. 2008. Available online: http://www.who.int/immunization/monitoring_surveillance/burden/estimates/Pneumo_ hib/en (accessed on 18 November 2019).

2. Wahl, B.; Sharan, A.; Deloria Knoll, M.; Kumar, R.; Liu, L.; Chu, Y.; McAllister, D.A.; Nair, H.; Campbell, H.; Rudan, I.; et al. National, regional, and state-level burden of Streptococcus pneumoniae and Haemophilus influenzae type B disease in children in India: Modelled estimates for 2000-2015. Lancet Glob. Health 2019, 7, e735-e747. [CrossRef]

3. Weinberger, D.M.; Malley, R.; Lipsitch, M. Serotype replacement in disease after pneumococcal vaccination. Lancet 2011, 378, 1962-1973. [CrossRef]

4. Balsells, E.; Guillot, L.; Nair, H.; Kyaw, M.H. Serotype distribution of Streptococcus pneumoniae causing invasive disease in children in the post-PCV era: A systematic review and meta-analysis. PLoS ONE 2017, 12, e0177113. [CrossRef]

5. Van Tonder, A.J.; Bray, J.E.; Quirk, S.J.; Haraldsson, G.; Jolley, K.A.; Maiden, M.C.; Hoffmann, S.; Bentley, S.D.; Haraldsson, Á.; Erlendsdóttir, H.; et al. Putatively novel serotypes and the potential for reduced vaccine effectiveness: Capsular locus diversity revealed among 5405 pneumococcal genomes. Microb. Genom. 2016, 2, 000090. [CrossRef]

6. Mostowy, R.J.; Croucher, N.J.; De Maio, N.; Chewapreecha, C.; Salter, S.J.; Turner, P.; Aanensen, D.M.; Bentley, S.D.; Didelot, X.; Fraser, C. Pneumococcal capsule synthesis locus cps as evolutionary hotspot with potential to generate novel serotypes by recombination. Mol. Biol. Evol. 2017, 34, 2537-2554. [CrossRef] [PubMed]

7. Henrichsen, J. Six newly recognized types of Streptococcus pneumoniae. J. Clin. Microbiol. 1995, 33, $2759-2762$. [PubMed]

8. Geno, K.A.; Gilbert, G.L.; Song, J.Y.; Skovsted, I.C.; Klugman, K.P.; Jones, C.; Konradsen, H.B.; Nahm, M.H. Pneumococcal capsules and their types: Past, present, and future. Clin. Microbiol. Rev. 2015, 28, 871-999. [CrossRef] [PubMed]

9. Bentley, S.D.; Aanensen, D.M.; Mavroidi, A.; Saunders, D.; Rabbinowitsch, E.; Collins, M.; Donohoe, K.; Harris, D.; Murphy, L.; Quail, M.A.; et al. Genetic analysis of the capsular biosynthetic locus from all 90 pneumococcal serotypes. PLoS Genet. 2006, 2, e31. [CrossRef] [PubMed]

10. Pichichero, M.E.; Khan, M.N.; Xu, Q. Next generation protein-based Streptococcus pneumoniae vaccines. Hum. Vaccin. Immunother. 2016, 12, 194-205. [CrossRef] [PubMed]

11. Pimenta, F.; Gertz REJr Park, S.H.; Kim, E.; Moura, I.; Milucky, J.; Rouphael, N.; Farley, M.M.; Harrison, L.H.; Bennett, N.M.; Bigogo, G.; et al. Streptococcus infantis, Streptococcus mitis, and Streptococcus oralis strains with highly similar cps5 loci and antigenic relatedness to serotype 5 pneumococci. Front. Microbiol. 2019, 9, 3199. [CrossRef]

12. Satzke, C.; Turner, P.; Virolainen-Julkunen, A.; Adrian, P.V.; Antonio, M.; Hare, K.M.; Henao-Restrepo, A.M.; Leach, A.J.; Klugman, K.P.; Porter, B.D.; et al. Standard method for detecting upper respiratory carriage of Streptococcus pneumoniae: Updated recommendations from the World Health Organization Pneumococcal Carriage Working Group. Vaccine 2014, 32, 165-179. [CrossRef] [PubMed] 
13. Austrian, R. Pneumococcal polysaccharide vaccines. Rev. Infect. Dis 1989, 11, S598-S602. [CrossRef] [PubMed]

14. Pai, R.; Gertz, R.E.; Beall, B. Sequential multiplex PCR approach for determining capsular serotypes of Streptococcus pneumoniae isolates. J. Clin. Microbiol. 2006, 44, 124-131. [CrossRef] [PubMed]

15. Jourdain, S.; Drèze, P.A.; Vandeven, J.; Verhaegen, J.; Van Melderen, L.; Smeesters, P.R. Sequential multiplex PCR assay for determining capsular serotypes of colonizing S. Pneumoniae. BMC Infect. Dis 2011, 11, 100. [CrossRef] [PubMed]

16. Marimón, J.M.; Ercibengoa, M.; Santacatterina, E.; Alonso, M.; Pérez-Trallero, E. Single-Step multiplex PCR assay for determining 92 pneumococcal serotypes. J. Clin. Microbiol. 2016, 54, 2197-2200. [CrossRef]

17. Marimón, J.M.; Morales, M.; Gamen, S.; Manrique, A.; Ercibengoa, M.; Cilla, G. A reverse-hybridization test for the identification of 76 pneumococcal serotypes, 42 individually and 34 in pairs. J. Microbiol. Methods 2017, 143, 13-16. [CrossRef]

18. Ercibengoa, M.; Alonso, M.; Vicente, D.; Morales, M.; Garcia, E.; Marimón, J.M. Utility of MALDI-TOF MS as a new tool for Streptococcus pneumoniae serotyping. PLoS ONE 2019, 14, e0212022. [CrossRef]

19. Lo, S.W.; Gladstone, R.A.; van Tonder, A.J.; Lees, J.A.; du Plessis, M.; Benisty, R.; Givon-Lavi, N.; Hawkins, P.A.; Cornick, J.E.; Kwambana-Adams, B.; et al. Pneumococcal lineages associated with serotype replacement and antibiotic resistance in childhood invasive pneumococcal disease in the post-PCV13 era: An international whole-genome sequencing study. Lancet Infect. Dis. 2019, 19, 759-769. [CrossRef]

20. Santiago, E.; Camacho, L.; Junquera, M.L.; Vázquez, F. Full HPV typing by a single restriction enzyme. J. Clin. Virol. 2006, 37, 38-46. [CrossRef]

21. Roberts, R.J.; Vincze, T.; Posfai, J.; Macelis, D. REBASE-restriction enzymes and DNA methyltransferases. Nucl Acids Res. 2005, 33, D230-D232. [CrossRef]

22. Fenoll, A.; Granizo, J.J.; Giménez, M.J.; Yuste, J.; Aguilar, L. Secular trends (1990-2013) in serotypes and associated non-susceptibility of $S$. pneumoniae isolates causing invasive disease in the pre-/post-era of pneumococcal conjugate vaccines in Spanish regions without universal paediatric pneumococcal vaccination. Vaccine 2015, 33, 5691-5699. [CrossRef] [PubMed]

23. Lawrence, E.R.; Arias, C.A.; Duke, B.; Beste, D.; Broughton, K.; Efstratiou, A.; George, R.C.; Hall, L.M. Evaluation of serotype prediction by cpsA-cpsB gene polymorphism in Streptococcus pneumoniae. J. Clin. Microbiol. 2000, 38, 1319-1323. [PubMed]

24. Batt, S.L.; Charalambous, B.M.; McHugh, T.D.; Martin, S.; Gillespie, S.H. Novel PCR-restriction fragment length polymorphism method for determining serotypes or serogroups of Streptococcus pneumoniae isolates. J. Clin. Microbiol. 2005, 43, 2656-2661. [CrossRef] [PubMed]

25. Camargo, D.R.; Pais, F.S.; Volpini, A.C.; Oliveira, M.A.; Coimbra, R.S. Revisiting molecular serotyping of Streptococcus pneumoniae. BMC Genom. 2015, 16. [CrossRef]

26. Brito, D.A.; Ramirez, M.; de Lencastre, H. Serotyping Streptococcus pneumoniae by multiplex PCR. J. Clin. Microbiol. 2003, 41, 2378-2384. [CrossRef]

27. Rubin, L.G.; Rizvi, A. PCR-based assays for detection of Streptococcus pneumoniae serotypes 3, 14, 19F and 23F in respiratory specimens. J. Med. Microbiol. 2004, 53, 595-602. [CrossRef]

28. Austrian, R. The quellung reaction, a neglected microbiologic technique. Mt. Sinai J. Med. 1976, 43, 699-709.

29. Lund, E. Laboratory diagnosis of Pneumococcus infections. Bull. World Health Organ. 1960, 23, 5-13.

30. Sørensen, U.B. Typing of pneumococci by using 12 pooled antisera. J. Clin. Microbiol. 1993, 31, $2097-2100$.

31. Mauffrey, F.; Fournier, É.; Demczuk, W.; Martin, I.; Mulvey, M.; Martineau, C.; Lévesque, S.; Bekal, S.; Domingo, M.C.; Doualla-Bell, F.; et al. Comparison of sequential multiplex PCR, sequetyping and whole genome sequencing for serotyping of Streptococcus pneumoniae. PLoS ONE 2017, 13, e0189163. [CrossRef]

32. Elberse, K.E.; van de Pol, I.; Witteveen, S.; van der Heide, H.G.; Schot, C.S.; van Dijk, A.; van der Ende, A.; Schouls, L.M. Population structure of invasive Streptococcus pneumoniae in The Netherlands in the pre-vaccination era assessed by MLVA and capsular sequence typing. PLoS ONE 2011, 6, e20390. [CrossRef] [PubMed]

33. Everett, D.B.; Cornick, J.; Denis, B.; Chewapreecha, C.; Croucher, N.; Harris, S.; Parkhill, J.; Gordon, S.; Carrol, E.D.; French, N.; et al. Genetic characterisation of Malawian pneumococci prior to the roll-out of the PCV13 vaccine using a high-throughput whole genome sequencing approach. PLoS ONE 2012, 7, e44250. [CrossRef] [PubMed] 
34. Dube, F.S.; van Mens, S.P.; Robberts, L.; Wolter, N.; Nicol, P.; Mafofo, J.; Africa, S.; Zar, H.J.; Nicol, M.P. Comparison of a real-time multiplex PCR and sequetyping assay for pneumococcal serotyping. PloS ONE 2015, 10, e0137349. [CrossRef] [PubMed]

35. Jaunekaite, E.; Tocheva, A.S.; Jefferies, J.M.; Gladstone, R.A.; Faust, S.N.; Christodoulides, M.; Hibberd, M.L.; Clarke, S.C. Current methods for capsular typing of Streptococcus pneumoniae. J. Microbiol. Methods 2015, 113, 41-49. [CrossRef] [PubMed]

36. Greenberg, D.; Hoover, P.A.; Vesikari, T.; Peltier, C.; Hurley, D.C.; McFetridge, R.D.; Dallas, M.; Hartzel, J.; Marchese, R.D.; Coller, B.G.; et al. Safety and immunogenicity of 15 -valent pneumococcal conjugate vaccine (PCV15) in healthy infants. Vaccine 2018, 36, 6883-6891. [CrossRef] [PubMed]

37. Guevara, M.; Ezpeleta, C.; Gil-Setas, A.; Torroba, L.; Beristain, X.; Aguinaga, A.; García-Irure, J.J.; Navascués, A.; García-Cenoz, M.; Castilla, J.; et al. Reduced incidence of invasive pneumococcal disease after introduction of the 13-valent conjugate vaccine in Navarre, Spain, 2001-2013. Vaccine 2014, 32, 2553-2562. [CrossRef]

38. Ercibengoa, M.; Arostegi, N.; Marimón, J.M.; Alonso, M.; Pérez-Trallero, E. Dynamics of pneumococcal nasopharyngeal carriage in healthy children attending a day care center in northern Spain. Influence of detection techniques on the results. BMC Infect. Dis. 2012, 12, 69. [CrossRef]

39. Menéndez, R.; España, P.P.; Pérez-Trallero, E.; Uranga, A.; Méndez, R.; Cilloniz, C.; Marimón, J.M.; Cifuentes, I.; Méndez, C.; Torres, A. The burden of PCV13 serotypes in hospitalized pneumococcal pneumonia in Spain using a novel urinary antigen detection test. CAPA study. Vaccine 2017, 35, 5264-5270. [CrossRef]

40. Torres, A.; Cillóniz, C.; Blasi, F.; Chalmers, J.D.; Gaillat, J.; Dartois, N.; Schmitt, H.J.; Welte, T. Burden of pneumococcal community-acquired pneumonia in adults across Europe: A literature review. Respir. Med. 2018, 137, 6-13. [CrossRef]

41. Marimón, J.M.; Ercibengoa, M.; Tamayo, E.; Alonso, M.; Pérez-Trallero, E. Long-Term epidemiology of Streptococcus pneumoniae serogroup 6 in a region of southern Europe with special reference to serotype $6 \mathrm{E}$. PLoS ONE 2016, 11, e0149047. [CrossRef]

42. Staples, M.; Graham, R.M.A.; Hicks, V.; Strachan, J.; Gonçalves da Silva, A.; Peverall, J.; Wicks, V.; Jennison, A.V. Discovery of Streptococcus pneumoniae serogroup 35 variants in Australian patients. Clin. Microbiol. Infect. 2017, 23, 476-479. [CrossRef] [PubMed]

43. Manna, S.; Ortika, B.D.; Dunne, E.M.; Holt, K.E.; Kama, M.; Russell, F.M.; Hinds, J.; Satzke, C. A novel genetic variant of Streptococcus pneumoniae serotype 11A discovered in Fiji. Clin. Microbiol. Infect. 2018, 24. [CrossRef] [PubMed]

(C) 2019 by the authors. Licensee MDPI, Basel, Switzerland. This article is an open access article distributed under the terms and conditions of the Creative Commons Attribution (CC BY) license (http://creativecommons.org/licenses/by/4.0/). 